\title{
Breastfeeding Recommendations. Pediatricians Mexicans Survey
}

\author{
H. Reyes-Vázquez ${ }^{1,2}$, C. Lopez-Enriquez¹, F. Bribiesca-Godoy³, A. Espinosa-Aguilera ${ }^{3}$, \\ B. M. Morfin-Maciel' ${ }^{4}$, N. E. Martínez-Aguilar ${ }^{*}$ \\ ${ }^{1}$ Hospital Español de México, Mexico City, Mexico \\ ${ }^{2}$ Pro-Breastfeeding Maternal Association APROLAM, Mexico City, Mexico \\ ${ }^{3}$ Hospital San José, Hospital General, Zamora, México \\ ${ }^{4}$ Hospital Infantil Privado, Mexico City, Mexico \\ ${ }^{5} \mathrm{CPDF}$, Hospital HMG, Mexico City, Mexico \\ Email: horacio2412@yahoo.com.mx, fbibriescag@gmail.com, blancamorfin@hotmail.com, ^noramar_dr@yahoo.com.mx
}

How to cite this paper: Reyes-Vázquez, H., Lopez-Enriquez, C., Bribiesca-Godoy, F., Espinosa-Aguilera, A., Morfin-Maciel, B.M. and Martínez-Aguilar, N.E. (2019) Breastfeeding Recommendations. Pediatricians Mexicans Survey. Open Access Library Journal, 6: e2816.

https://doi.org/10.4236/oalib.1102816

Received: June 13, 2016

Accepted: May 6, 2019

Published: May 9, 2019

Copyright $\odot 2019$ by author(s) and Open Access Library Inc.

This work is licensed under the Creative Commons Attribution International License (CC BY 4.0).

http://creativecommons.org/licenses/by/4.0/

\begin{abstract}
Objective: To know recommendations on breastfeeding by Mexican pediatricians. Methods: Cross-sectional, descriptive study conducted through a survey of Mexican pediatricians. Results: Two hundred and fifty-four pediatricians (range 27 to 72 years) were surveyed. Most of them worked in public hospital or private practice or both. Among them $94.5 \%$ recommended newborn early contact with mother and $54.3 \%$ rooming. Exclusive breastfeeding was suggested by $89.8 \%$, out of them $51.9 \%$ for 6 months. Breastfeeding on demand was counseled by $88.2 \%$ and $84.6 \%$ without fixed schedules. Pacifier use was rejected by $86.6 \%$. $51.2 \%$ used iron supplements and $59.5 \%$ used other vitamins. Stopping breastfeeding in special situations was suggested by 87.4\%; of them, $86.6 \%$ in case of infection with AIDS; $74.4 \%$ if the mother used drugs; $74.4 \%$ by infection with hepatitis B virus; $49.6 \%$ in case of mastitis; $17.3 \%$ in newborns with jaundice; and $18.5 \%$ in other situations. Finally, 93.3\% of pediatricians surveyed reported interest in breastfeeding; $54.7 \%$ obtained information in medical journals; 54.7\% through medical courses, and $31.9 \%$ in books. $58.3 \%$ of respondents oriented on breastfeeding according to WHO recommendations; $31.5 \%$ did so regularly and $10.2 \%$ did not. Conclusions: Pediatricians play a major role in breastfeeding promotion, but their formation is scarce and they are not prepared to counsel patients. Governments of developing countries should promote breastfeeding to ensure the health and proper development of infants.
\end{abstract}

\section{Subject Areas}

Pediatrics 


\section{Keywords}

Breastfeeding, Pediatricians, Recommendations, Promotion, Contraindications

\section{Background}

Breastfeeding (BF) is vital for survival, health and child development; however, Mexico has a low percentage of breastfeed women. Percentage of exclusive breastfeeding (EBF) children has fallen dramatically from $21 \%$ in 2006 to $14 \%$ in 2012 [1]. This fact becomes relevant for the adverse impact it may have on infants' health. BF has an excellent nutritional value, plus a prebiotic effect that favors the development of beneficial gastrointestinal flora (bifidobacteria), which for its anti-inflammatory and antioxidant effect prevents the necrotizing enterocolitis development [2] and its immunostimulant action (in both, innate and acquired immunity) confers a protective effect decreasing severity and incidence of gastrointestinal and respiratory infections [2] [3] [4] [5] [6], improving their prognosis. Likewise breastfeeding is associated with a lower incidence of postnatal death [5], a lower incidence of obesity and diabetes [7], as well as significant differences in cognitive development and vision, when compared to infants fed human milk substitutes [8]. BF also provides benefits to mothers, lower postpartum hemorrhage and decreasing the risk of developing ovarian or breast cancer, and a spacing pregnancies method [9] [10]. Some studies reported a reduction in atopic dermatitis incidence in patients with EBF in the first 6 months. $\mathrm{BF}$ effect in the prevention of allergic diseases is controversial [11] [12].

The World Health Organization (WHO) and the American Academy of Pediatrics (AAP) recommend EBF during the first six months of life. Then, complementary feeding should start and keeping breastfeeding during the first two years of life [13] [14]. There is a higher prevalence of BF among low education women and housewives [15]. By reducing the duration of BF of children, regardless of economic status, hygiene, food and access to services, health is negatively affected.

In rural areas and in low socioeconomic groups, prolonging breastfeeding for the first year of life is associated with a better chance of surviving in this period [13]. Among the factors driving the decline in BF are: the perception of insufficient milk production, lack of nutritional value of human milk, scheduling conflicts with work and inconvenience of congestion of the breasts and cracking of nipples [16].

Mexico has published several practices of breastfeeding and weaning studies. Results show that, over time, EBF has lost importance and mixed feeding, resulting from the combination of breast milk and administration of industrialized milk, it has become more frequent [17]. Other studies suggest that a history of contact with health personnel, through prenatal care and delivery, both public 
and private services, is associated with a shorter duration of breastfeeding; as often is the same doctor who recommends adding other milk to the diet of children, and even some, sell or give away samples of infant formulas [18] [19].

Despite the already noted, they are insufficient studies on breastfeeding and infant feeding characteristics in Mexico, as well as its determinants. The following discussion is intended to document the recommendations of pediatricians, over breastfeeding, because they are, in most cases, the first contact with mothers and those responsible for giving the necessary information on human milk.

\section{Material and Methods}

In May 2012, it was carried out a cross-sectional, descriptive, open study through a survey conducted in May to 254 Mexican pediatricians. The population registered in the congress of pediatricians, at the moment of carrying out the survey, was of 2500 doctors, for which, with a sample of 254 doctors surveyed, a margin of error of $5.8 \%$ is obtained. With a confidence interval of $95 \%$ and a heterogeneity of $50 \%$. Responsible for obtaining the information were doctors who had no role in the resolution of the survey. The questionnaire includes data on: age and gender of physicians, type of medical practice, work area, and recommendations: prenatal visits, early mother-infant contact, rooming, EBF time, vitamin supplements and pacifier use; as well as a place of information. Univariate analysis of the data was done to calculate prevalence and percentages. At the start of the survey, the interviewees signed their authorization to answer the questions.

\section{Results}

\subsection{Surveyed Population}

Demographic characteristics of respondents' pediatricians are shown in Table 1.

\subsection{Knowledge and Attitudes of Pediatricians Surveyed on Breastfeeding}

From the 254 physicians surveyed pediatricians, 143 (56.3\%) had not usual do a prenatal visit. Once the baby was born, $240(94.5 \%)$ recommended early contact with mother and 138 (54.3\%) rooming. The EBF was recommended by 228 $(89.8 \%)$ and $132(51.9 \%)$ suggested it for 6 months. 224 pediatricians (88.2\%) recommended BF, 215 (84.6\%) recommended it on demand, without fixed schedules. 52.8\% (134) of pediatricians, recommended the first medical visit at 7 days old.

Regarding the pacifier use, it is interesting that $220(81.1 \%)$ respondents rejected its use, while $12.5 \%$ (34) advised its use. Recommendations on supplements use are shown in Table 2.

\subsection{Breastfeeding Contraindications}

When pediatricians believe that $\mathrm{BF}$ posed a medical problem, most of them 
91.3\%, decided to suspend it without going to another specialist. Similarly, most respondents pediatricians recommended to stop breastfeeding if mothers have HIV, hepatitis or addictions. These doctors believe that almost $40 \%$ of mothers did not breastfeeding for different reasons (simply refuse, flat nipple, low birth weight, teenage mother, decreased milk production, gastroesophageal reflux). This data indicate that more than third part of recommendations made by referees pediatricians regarding the continuation or $\mathrm{BF}$ withdrawal, were incorrect (Table 3).

\subsection{Breastfeeding Contraindicated Drugs}

Medical behavior was highly variable to indicate the cessation of breastfeeding if the mother takes any drugs. Mainly with the most commonly used drugs as: antineoplastic drugs, metronidazole, anticonvulsants, chloramphenicol, antihypertensive drugs, antipsychotics, antithyroid drugs and ciprofloxacin as shown in Table 4.

Table 1. Demographic characteristics of the surveyed pediatricians.

\begin{tabular}{|c|c|c|}
\hline Pediatricians & $\begin{array}{c}\text { Total } \\
\mathrm{N}=254\end{array}$ & (\%) \\
\hline \multicolumn{3}{|l|}{ Gender } \\
\hline Male & 163 & $(64.2)$ \\
\hline Female & 91 & $(35.8)$ \\
\hline \multicolumn{3}{|l|}{ Age (years) } \\
\hline $26-29$ & 1 & $(0.4)$ \\
\hline $30-39$ & 61 & (24) \\
\hline $40-49$ & 115 & $(45.3)$ \\
\hline $50-59$ & 64 & $(25.2)$ \\
\hline$\geq 60$ & 13 & (5.1) \\
\hline \multicolumn{3}{|l|}{ Work area } \\
\hline Urban & 223 & $(87.8)$ \\
\hline Suburban & 26 & $(10.2)$ \\
\hline Rural & 5 & (1.9) \\
\hline \multicolumn{3}{|l|}{ Pediatric practice } \\
\hline Without practice & 33 & (12.9) \\
\hline With Clinical Practice: & 221 & $(87.1)$ \\
\hline$\underline{\text { Public }}$ & 128 & $(50.3)$ \\
\hline Individual & 15 & $(5.9)$ \\
\hline In group & 5 & $(1.9)$ \\
\hline In hospital & 108 & $(42.5)$ \\
\hline Private & 93 & (36.6) \\
\hline Individual & 59 & $(23.2)$ \\
\hline In group & 23 & $(9.1)$ \\
\hline In hospital & 11 & $(4.3)$ \\
\hline Mixed practice & 113 & $(44.5)$ \\
\hline
\end{tabular}


Table 2. Use recommendation of vitamins and iron by surveyed pediatricians.

\begin{tabular}{ccc}
\hline Supplements & Recommended & Not recommended \\
\hline Vitamins & $151(59.44 \%)$ & $103(40.55 \%)$ \\
Iron & $118(46.45 \%)$ & $136(53.54 \%)$ \\
\hline
\end{tabular}

Table 3. Incorrect recommendations about removal and/or continuation of breastfeeding, conducted by surveyed pediatricians.

\begin{tabular}{cc}
\hline Situation & Percentage of incorrect recommendation (\%) \\
\hline HIV infection & 12.6 \\
HBV infection & 74.4 \\
Drug users & 13.4 \\
Mastitis & 49.6 \\
Jaundice infants & 17.3 \\
Mother denial & 31.5 \\
Other & 18.5 \\
Average & 36.2 \\
\hline
\end{tabular}

Table 4. Doctors' behavior about breastfeeding related to use different drugs-medication.

\begin{tabular}{ccc}
\hline Drug & \multicolumn{2}{c}{ Breastfeeding contraindication } \\
n (\%) \\
Antineoplastic & 93 & $(36.61 \%)$ \\
Metronidazole & 40 & $(15.74 \%)$ \\
Anticonvulsant & 28 & $(11 \%)$ \\
Chloramphenicol & 25 & $(9.8 \%)$ \\
Antihypertensive & 25 & $(9.8 \%)$ \\
Antidepressant & 24 & $(9.4 \%)$ \\
Antithyroid & 24 & $(9.4 \%)$ \\
Antipsychotic & 16 & $(6.2 \%)$ \\
Ciprofloxacin & 15 & $(5.9 \%)$ \\
\hline
\end{tabular}

\subsection{Continuous Education}

Finally 237 (93.3\%) of pediatricians surveyed referred breastfeeding interest in, 139 (54.7\%) obtain information from medical supplies; 139 (54.7\%) in courses and 81 (31.9\%) of books. As for the knowledge self-perception; 58.3\% (148) of respondents mentioned proper management of $\mathrm{BF}, 31.5 \%$ (80) referred self-rated handling as fair and $10.2 \%$ (26) said that does not properly handle it.

\section{Discussion}

Breastfeeding is the natural way to provide the newborn with necessary nutrients for normal growth and somatic and brain development, protecting it from infec- 
tious disease, obesity and other no communicable diseases such as diabetes. Overall only $38 \%$ of children receive EBF in the first 6 months of life [20]. Various, social, occupational and family factors hinder this practice. In Mexico, the prevalence of EBF decreased from $22.3 \%$ in 2006 to $14 \%$ in 2012 [1]. The decline in the BF is explained by the increase in children who consumed other formulas or water. Also, the introduction of complementary foods increased as the BF fell [21]. This study explored the pediatricians' recommendations regarding this practice.

Among the demographic characteristics of the surveyed population, often males (1.6:1) were found. $96.4 \%$ were older than 30 years; almost $90 \%$ had mixed and work in urban areas, so we can infer that the pediatrician who works in the city, has increased access to academic events, in which BF is promoted; but assumes importance that in rural areas between 2006 and 2012, EBF dropped from $36.9 \%$ to $18.5 \%$, proportionately greater decline, than in the urban area [21].

Regarding the EBF duration, both WHO [13] [20], as the Mexican Official Norm [22], advices promote EBF for the first 6 months of life on demand. Of those surveyed pediatricians, $89.8 \%$ recommend BF for 6 months, as well as the use of free demand (88.2\%) and without a fixed schedule (84.6\%). In Mexico, the $\mathrm{BF}$ average duration is 10.2 months, but only $14.4 \%$ give EBF the first 6 months [21]. The national health survey of Mexico (2012) reported that the reasons for mothers who never breastfed, are: $37 \%$ lack of milk production, disease $14 \%$, $11 \%$ that the child did not want chest, and 5\% prescription drugs [21]. These numbers reflect the importance that breastfeeding mothers receive enough information to maintain lactation at least 6 months, and this information must be provided by the medical staff and nearby paramedics.

Although $56.3 \%$ of pediatricians did not perform prenatal visit, $94.5 \%$ recommended early contact with mother, and 54.3\% rooming. Studies in Mexico City maternities, have been shown that this practice promotes EBF management, regardless of whether the product was obtained by delivery or cesarean [23] [24].

81.1\% pediatricians Mexicans surveyed, reject the use of pacifier. In a Portuguese study, pacifier use, discouraged the EBF in $41 \%$ of mothers [25]. In an European prospective study, between 2000 and 2008, the non-promotion in pacifier use, increased EBF from $33.6 \%$ to $48.1 \%$ [26].

Iron supplements, folic acid and vitamins during pregnancy and lactation reduce the risk of anemia in mother. However these supplements in breastfed babies before 6 months life do not increase their hemoglobin levels. The prevalence of iron deficiency anemia in breastfed children who do not receive supplements is very low $(<3 \%)$ [27]; not after 6 months, in which the iron elevates serum ferritin and hemoglobin levels, these being major effects on anemic children. Therefore, vitamin supplements are recommended for children over 6 months [28]. The National Health Survey 2012, reported that complementary feeding in Mexico has improved in quality and frequency [29]. The percentage of children who consume foods rich in iron, introducing other foods and diet diversity of 
the children in their second half of life, recorded positive changes. Between 2006 and 2012, consumption of iron-rich foods between 6 and 11 months increased $50.5 \%$ to $55.9 \%$; the introduction of solid, semi-solid and soft foods between 6 and 8 months increased from $88.5 \%$ to $94.8 \%$ and the minimum dietary diversity between 6 and 11 months increased from 64.4\% to 74\% [21] [29]. Among respondents' Mexican pediatricians, vitamins and iron supplements during lactation, were recommended by $59.5 \%$ and $51.2 \%$ respectively. In a survey conducted in the US, $36.4 \%$ of pediatricians recommend the use of vitamin D supplementation in breastfed infants; yet only $3 \%$ of parents that believed BF covering all children requirements, gave the supplement [30].

A common reason for suspending $\mathrm{BF}$ is the fear of maternal transmission of infection through the milk. It is known that both HIV and HBV are secreted in breast milk. In HIV, BF is contraindicated, since transmission depends on the maternal viral load, mother immune status and BF pattern and duration [31]. Present study showed, $87.4 \%$ of pediatricians surveyed recommended suspending feeding if the mother has HIV.

For drug-addicted mothers, BF is contraindicated [32]; 86.6\% of Mexicans pediatricians surveyed agreed with this recommendation. In the case of hepatitis $\mathrm{B}$, WHO recommends not stop BF in mothers infected with $\mathrm{HBV}$, even in areas of high infectivity without availability vaccine [33]. The $4.32 \%$ of infants born from mothers with hepatitis B HBV, develop hepatitis B. But the transmission usually occurs at the time of delivery, and less frequently "in utero" or through $\mathrm{BF}[33]$.

A recent meta-analysis reported that risk of becoming infected with $\mathrm{HBV}$ is similar in-BF from her own mother children, than in children receiving maternalized formulations [OR $=-0.8 \%(95 \% \mathrm{CI}:-1.6 \%, 0.1 \%)][34]$; so that the recommendation is that mothers with $\mathrm{HBV}$ can breastfeed, just if they were vaccinated between the first 24 hours of life, and receive two additional doses in the first 6 months. If mothers have breast or nipples cracked and bleeding, should postpone breastfeeding until healed injuries [33] [34].

$74.4 \%$ of respondents' Mexican pediatricians recommended suspending BF in case of hepatitis B. This recommendation is similar to that made of 25\% Australian gynecologists [35], and 50\% of US hepatologists [36].

The use of medications in $\mathrm{BF}$ is not a contraindication to continue it. Unjustified recommendation comes from a doctor or nurse. Most medicines that are prescribed in BF have no effect on the baby [32]. Mastitis is caused by infectious agents such as Staphylococcus aureus and Streptococcus agalactiae, needed the antibiotics and NSAIDs use [37].

It is recommended to continue BF by manually removing milk and review newborn suction technique [38]. 49.6\% of Mexican pediatricians advised to suspend BF in mastitis case. Some children receiving mother's BF have physiologic jaundice, which can last until after the third week, which does not represent a contraindication to further the BF [39]. 17.3\% of pediatricians sur- 
veyed advised to suspend the $\mathrm{BF}$ in case of neonatal jaundice. This data together indicate that $36.2 \%$ of the recommendations made by pediatricians in relation to the withdrawal of breastfeeding, were incorrect.

Antineoplastic drugs, because they alter the nucleic acid synthesis in both, mother and therefore the child, properly considered contraindicated by the $36.61 \%$ of pediatricians. Although only thalidomide and methotrexate are absolutely contraindicated during pregnancy and lactation, alternatives to ciprofloxacin and sodium phosphate should also be considered for pregnant and BF women.

$\mathrm{BF}$ is also recommended during treatment with cyclosporine, metronidazole and ciprofloxacin. However, in some cases, treatment with preparations of 5-aminosalicylic acid, corticosteroids, thiopurines and TNF inhibitors, can be accepted during pregnancy and lactation [40].

Metronidazole is excreted into breast milk in insignificant quantities and there are not reported problems in infants whose mothers were administered. Metronidazole is compatible and safe for BF and infant, yet it was contraindicated for $15.7 \%$ of pediatricians [41]. Anticonvulsants are accepted, with mild or unlikely risk, are excreted in breast milk in varying proportions, can reach clinically relevant concentrations. Should be considered alertness and fed properly. Also should be monitored plasma levels in infants, whether if sedation appears and to lead progressively weaning, mainly with phenobarbital. Other anticonvulsants generally do not exhibit BF contraindication [42]. BF was contraindicated only by $11 \%$ of pediatricians.

25 doctors contraindicated chloramphenicol use, it is unsafe and you need to carefully assess their use. It's excreted in breast milk and there is a possibility of occurrence of neonatal gray syndrome, besides the possibility of aplastic anemia, dose independent, so that the use of other safer antimicrobial is recommended, although topically has not been outlawed [43].

25 respondents pediatricians contraindicated antihypertensive drugs. There are really few antihypertensive drugs contraindicated in infancy such as acebutolol, atenolol, prazocin and diazoxide, others are not contraindicated to breastfeeding and have a wide safety margin [44].

On the issue of antidepressants, most of them there are not a contraindication to breastfeeding. However, in the 1st. month of life can cause cramps, irritability, insomnia, outside this period have no side effects [45] but were contraindicated by 24 physicians.

Antithyroid drugs in general have not been reported side effects in infants whose mothers take them for long time, with thyroid hormones levels and psychomotor development, normal in infants. No contraindications to BF, they are safe in the long and short term, but 24 doctors banned them [46].

Antipsychotics, some as lithium, are at high risk, and reaching levels up to $50 \%$ in infants, there have been toxicity reports with cyanosis and hypotony. As alternatives lamotrigine, carbamazepine or valproic acid, are recommended [47] 
but some as lithium, were contraindicated by 16 doctors. 15 doctors contraindicated Ciprofloxacin, but it is an antibiotic compatible with BF, it has not been demonstrated side effects in infants whose mothers received it. It is excreted in breast milk in small amounts and have not been shown blood levels or very low [41].

Misinformation has been worldwide documented. In 1999, the AAP conducted a BF survey self-administered to 1602 pediatricians. $71 \%$ of respondents; $65 \%$ recommended the $\mathrm{BF}$ as the only food for the first month. $37 \%$ recommended prolonging $\mathrm{BF}$ for one year. Most pediatricians felt that formulas were equally convenient that maternal breast to feeding a baby, but recognized that they needed more education on this topic. Most doctors recommended suspending the breast with treatments that are known not to oppose BF [48].

In a national survey in North America participated 3115 residents and 1920 pediatricians, family physicians and obstetricians, attended the response rate was $68 \%$. All groups showed ignore BF benefits. Less than $50 \%$ of residents know what to do in special situations. More than $30 \%$ of doctors advised incorrectly. Residents reported that their knowledge came from theoretical sources. Only $55 \%$ of residents reported on occasion have addressed the issue and less than $20 \%$ had shown the techniques at least 5 times during residency. $50 \%$ of physicians reported inadequate training. $90 \%$ reported promote $\mathrm{BF}$, but only $50 \%$ did so effectively [49].

Supported by pediatricians, it is essential to promote EBF. Among respondents' Mexican pediatricians, $93.3 \%$ reported interest in BF. 54.7\% obtained medical information from articles; $54.7 \%$ in courses and $31.9 \%$ in books. In Canada were randomly questioned 999 pediatric residents and 610 pediatricians to assess knowledge and skills. They answered $74 \%$ and $69 \%$ respectively. $90 \%$ said the pediatrician should support BF, but the experience and knowledge they received at residence were scarce. More than 25\% of each group felt that BF was not more beneficial to feed the baby. Advices to suspend BF or start the formula were inadequate in most. Only $64 \%$ of pediatricians and $52 \%$ of residents knew that giving supplemental formula in early weeks, favored BF failure. For both groups, personal experiences (own or with wife) were so determined to gain knowledge and confidence in promoting breast. Residents had acquired knowledge in books. $70 \%$ of pediatricians recommended devoting more time to training in this topic. The study showed that residents' training to promote BF is inadequate; it is urgent implement academic programs [50].

In general, knowledge, attitudes and doctors beliefs of regarding the $\mathrm{BF}$ are bad. A Canadian study assessed these topics via a questionnaire completed by 397 pediatricians. The concepts were adequate in $67.8 \%$. $74.2 \%$ was declared with jurisdiction to give advice on skills to BF. $49.6 \%$ said that BF was a family doctor responsibility. Only 5.3\% watched the process in the mother-son binomial. [51] 58.3\% of Mexicans pediatricians surveyed considered conducting appropriate $\mathrm{BF}$ management; $31.5 \%$ reported handling self-rated as fair in $\mathrm{BF}$ and 
$10.2 \%$ said that does not properly handle the same, indicating that training should be promoted on this topic during residency.

Between the strengths of this study are, the choice of the surveyed population (pediatricians only), anonymity and that being a closed questionnaire, prevents the spread of information, which helps to get specific, useful and reliable data. Among its weaknesses it is a closed questionnaire, limiting the possible response options. The lack of flexibility will make the responses lack depth in specific points.

\section{Conclusion}

BF promotion is a multidisciplinary work that includes pediatricians, family doctors, gynecologists, nurses, social workers and residents. Pediatricians, given its proximity with mother-son binomial, need to receive more information during their training, in order that they can promote BF effectively. There is not really a suitable substitute for BF. Governments from economically vulnerable countries should encourage $\mathrm{BF}$ practice, promoting and facilitating this to working mothers, to ensure health and infants well being.

\section{Limitations}

The limitations of this study include the fact that issuing a recommendation depends on the physician's preparation and expertise, an item that was not included in the survey.

\section{Declaration of Conflicting Interests}

Participation did so freely and voluntarily. We (all the authors) declare, that there is no conflict of interest.

This research received No specific grant from any funding agency in the public, commercial or not for profit sectors.

\section{Acknowledgements}

Thanks to APROLAM (Asociación Pro-lactancia Materna), CONAPEME (Confederación Nacional de Pediatría de México), CPDF (Colegio de Pediatría del Distrito Federal).

\section{References}

[1] Colchero, M.A., Contreras-Loya, D., López Gatell, H. and González de Cosio, T. (2015) The Costs of Inadequate Breastfeeding of Infants in Mexico. The American Journal of Clinical Nutrition, 101, 579-586. https://doi.org/10.3945/ajcn.114.092775

[2] Pacheco, A.R., Barile, D., Underwood, M.A. and Mills, D.A. (2015) The Impact of the Milk Glycobiome on the Neonate Gut Microbiota. Annual Review of Animal Biosciences, 16, 419-445. https://doi.org/10.1146/annurev-animal-022114-111112

[3] Valentino Coppa, G., Gabrielli, O., Bertino, E., Zampini, L., Galeazzi, T., Padella, L., et al. (2013) Human Milk Glycosaminoglycans: The State of the Art and Future Perspective. Italian Journal of Pediatrics, 39, 2-8. 
https://doi.org/10.1186/1824-7288-39-2

[4] Howie, P.W., Forsgth, J.S., Ogston, S.A., Clark, A. and duFlorey, C. (1990) Protective Effect of Breast Feeding against Infection. British Medical Journal, 300, 11-16. https://doi.org/10.1136/bmj.300.6716.11

[5] Chen, A. and Rogan, W.J. (2004) Breastfeeding and the Risk of Postneonatal Death in the United States. Pediatrics, 113, e435-e439. https://doi.org/10.1542/peds.113.5.e435

[6] Victora, C.G., Barros, F.C., Vaughan, J.P. and Tlixeira, A.R.M. (1987) Evidence for Protection by Breast-Feeding against Infant Deaths from Infectious Diseases in Brazil. The Lancet, 8, 319-322. https://doi.org/10.1016/S0140-6736(87)90902-0

[7] Horta, B.L., de Mola, C.L. and Victoria, C.G. (2015) Long-Term Consequences of Breastfeeding on Cholesterol, Obesity, Systolic Blood Pressure, and Type-2 Diabetes: Systematic Review and Meta-Analysis. Acta Paediatrica, 104, 30-37. https://doi.org/10.1111/apa.13133

[8] Andres, A., Cleves, M.A., Bellando, J.B., Pivik, R.T., Casey, P.H. and Badger, T.M. (2012) Developmental Status of 1 Year Old Infants Fed Breast Milk, Cow's Milk Formula, or Soy Formula. Pediatrics, 129, 1134-1140. https://doi.org/10.1542/peds.2011-3121

[9] Romieu, I., Hernández-Avila, M., López, L. and Romero-Jaime, R. (1996) Breast Cancer and Lactation History in Mexican Women. American Journal of Epidemiology, 143, 543-552. https://doi.org/10.1093/oxfordjournals.aje.a008784

[10] Thapa, S., Short, V.R. and Potts, M. (1988) Breast-Feeding, Birth Spacing and Their Effects on Child Survival. Nature, 335, 679-682. https://doi.org/10.1038/335679a0

[11] Mihrshahi, S., Ampon, R., Webb, K., Almqvist, C., Kemp, A.S., Hector, D., et al. (2007) The Association between Infant Feeding Practices and Subsequent Atopy among Children with a Family History of Asthma. Clinical \& Experimental Allergy, 37, 671-679. https://doi.org/10.1111/j.1365-2222.2007.02696.x

[12] Wegienka, G., Zoratti, E. and Cole, J.C. (2015) The Role of the Early-Life Environment in the Development of Allergic Disease. Immunology and Allergy Clinics of North America, 35, 1-17. https://doi.org/10.1016/j.iac.2014.09.002

[13] World Health Organization (2003) Global Data Bank and Breastfeeding.

[14] American Academy of Pediatrics. https://www2.aap.org/breastfeeding/faqsBreastfeeding.html

[15] Rivera-Pasquel, M., Escobar-Zaragoza, L. and González de Cosío, T. (2015) Breastfeeding and Maternal Employment: Results from Three National Nutritional Surveys in Mexico. Maternal and Child Health Journal, 19, 1162-1172. https://doi.org/10.1007/s10995-014-1622-9

[16] Winikoff, B. and Laukaran, V.H. (1989) Breast-Feeding and Bottle-Feeding Controversies in the Developing World: Evidence from a Study in Four Countries. Social Science \& Medicine, 29, 859-868. https://doi.org/10.1016/0277-9536(89)90085-3

[17] González de Cosío, T., Escobar-Zaragoza, L., González-Castell, D., Reyes-Vázquez, H. and Rivera-Dommarco, J.A. (2013) Breastfeeding in Mexico Was Stable, on Average, But Deteriorated among the Poor, Whereas Complementary Feeding Improved: Results from the 1999 to 2006 National Health and Nutrition Survey. The Journal of Nutrition, 143, 664-671. https://doi.org/10.3945/jn.112.163097

[18] Margen, S., Melnick, V., Neuhauser, L. and Ríos, E. (1991) Infant-Feeding in Mexico: A Study of Health Facilities and Mothers Practices in Three Regions. Nestlé Infant Formula Audit Commission, Emoryville. 
[19] Victora, C.G., Huttly, S.R.A., Barros, F.C., Martínez, J.C. and Vaughan, J.P. (1991) Prolonged Breast-Feeding and Malnutrition: Confounding and Effect Modification in a Brazilian Cohort Study. Epidemiology, 2, 175-181. https://doi.org/10.1097/00001648-199105000-00003

[20] Recomendaciones de la WAO sobre lactancia maternal. http://www.who.int/topics/breastfeeding/en

[21] González de Cosío, T., Escobar-Zaragoza, L., González Castell, L.D. and Rivera-Dommarco, J.A. (2013) Infant Feeding Practices and Deterioration of Breastfeeding in Mexico. Salud Pública de México, 55, s170-s179.

[22] Norma Oficial Mexicana (NOM-043-SSA2-2013), apéndice F. http://www.dof.gob.mx/nota_detalle.php?codigo $=5285372 \&$ fecha $=22 / 01 / 2013$

[23] Flores-Huerta, S. and Cisneros-Silva, I.E. (1997) Mother-Infant Rooming-In and Exclusive Breastfeeding. Salud Pública de México, 39, 110-116. https://doi.org/10.1590/S0036-36341997000200004

[24] Cisneros-Silva, I.E., Flores-Huerta, S. and Rosas-Gallegos, M.C. (1995) Mother-Infant Rooming-In and Beginning of Breast Feeding in a Tertiary Care Hospital. Salud Pública de México, 37, 424-429.

[25] Alves, A.L., Oliveira, M.I. and Moraes, J.R. (2013) Breastfeeding-Friendly Primary Care Unit Initiative and the Relationship with Exclusive Breastfeeding. Revista de Saúde Pública, 47, 1130-1140.

[26] Forrester-Knauss, C., Merten, S., Weiss, C., Ackermann-Liebrich, U. and Zemp Stutz, E. (2013) The Baby-Friendly Hospital Initiative in Switzerland: Trends over 9-Year Period. Journal of Human Lactation, 29, 510-516. https://doi.org/10.1177/0890334413483923

[27] Ziegler, E.E., Nelson, S.E. and Jeter, G.M. (2009) Iron Supplementation of Breastfed Infants from an Early Age. The American Journal of Clinical Nutrition, 89, 525-532. https://doi.org/10.3945/ajcn.2008.26591

[28] Nagpal, J., Sachdev, H.P., Singh, T. and Mallika, V. (2004) A Randomized Placebo-Controlled Trial of Iron Supplementation in Breastfed Young Infants Initiated on Complementary Feeding: Effect on Hematological Status. Journal of Health, Population and Nutrition, 22, 203-211.

[29] Encuesta Nacional de Salud 2012. http://ensanut.insp.mx/doctos/analiticos/DeterioroPracLactancia.pdf

[30] Taylor, J.A., Geyer, L.J. and Feldman, K.W. (2010) Use of Supplemental Vitamin d among Infants Breastfed for Porlonged Periods. Pediatrics, 125, 105-111. https://doi.org/10.1542/peds.2009-1195

[31] ESPGHAN Committee on Nutrition (2009) Breastfeeding: A Commentary by the ESPGHAN Committee on Nutrition. Journal of Pediatric Gastroenterology and Nutrition, 49, 112-115. https://doi.org/10.1097/MPG.0b013e31819f1e05

[32] Ward, R.M., Bates, B.A., Benitz, W.E., Burchfield, D.J., Ring, J.C., Walls, R.P., et al. (2001) The Transfer of Drugs: An Other Chemicals into Human Milk. Pediatrics, 108, 776-789. https://doi.org/10.1542/peds.108.3.776

[33] Ahn, J., Salem, S.B. and Cohem, S.M. (2010) Evaluation and Management of Hepatitis B in Pregnancy: A Survey of Current Practices. Gastroenterology \& Hepatology, 6, 570-578.

[34] World Health Organization (1998) Hepatitis B and Breastfeeding. Journal of the International Association of Physicians in AIDS Care, 4, 20-21.

[35] Zheng, Y., Lu, Y., Ye, Q., Xia, Y., Zhou, Y., Yao, Q., et al. (2011) Should Chronic 
Hepatitis B Mothers Brestfeed? A Meta Analysis. BMC Public Health, 11, 502. https://doi.org/10.1186/1471-2458-11-502

[36] Giles, M.L., Garland, S.M., Grover, S.R., Lewin, S.M. and Hellard, M.E. (2006) Impact of an Education Campaign on Management in Pregnancy of Women Infected with a Blood-Borne Virus. The Medical Journal of Australia, 184, 389-392.

[37] Delgado, S., Arrollo, E., Jiménez, E., Fernández, L. and Rodriguez, J.M. (2009) Mastitis infecciosa durante la lactancia. Un problema infravalorado. Acta Pediátrica Es pañola, 67, 77-84.

[38] National Institute for Health and Clinical Excellence (2006) NICE Clinical Guide 37. Routine Postnatal Care of Women and Their Babies. http://guidance.nice.org.uk/cg37

[39] Gartner, L.M. (2001) Breastfeeding and Jaundice. Journal of Perinatology, 21, S25-S29. https://doi.org/10.1038/sj.jp.7210629

[40] Mendoza, L.E. and Humana, L. (2011) Medicamentos, hierbas y tóxicos en lactancia materna. Edit. Panamericana, 320-335.

[41] Nielsen, O.H., Maxwell, C. and Hendel, J. (2014) IBD Medications during Pregnancy and Lactation. Nature Reviews Gastroenterology \& Hepatology, 11, 116-127. https://doi.org/10.1038/nrgastro.2013.135

[42] Davanzo Dal Bo, S., Bua, J., Copertino, M., Zanelli, E. and Matarazzo, L. (2013) Antiepileptic Drugs and Brastfeeding. Italian Journal of Pediatrics, 39, 50-61. https://doi.org/10.1186/1824-7288-39-50

[43] Hale, T. (2014) Medication and Mothers Milk. 16th Edition, Hale Publishing, Amarillo, 128-129.

[44] Ref Ghanem, F.A. and Movahed, A. (2008) Use of Antihypertensive Drugs during Pregnancy and Lactation. Cardiovascular Therapeutics, 26, 38-49. https://doi.org/10.1111/j.1527-3466.2007.00036.x

[45] Sachs, H.C. (2013) The Transfer of Drugs and Therapeutics into Human Breast Milk: An Update of Selective Topics. Pediatrics, 132, e795-e809. https://doi.org/10.1542/peds.2013-1985

[46] Serrano Aguayo, P., García de Quiros Muñoz, J.N., Breton, L.I. and Cozar León, M.V. (2015) Tratamiento de enfermedades endocrinológicas durante la lactancia. Medicina Clínica, 144, 73-79. https://doi.org/10.1016/j.medcli.2014.04.021

[47] Rowe, H., Baker, T. and Hale, T.W. (2013) Maternal Medication, Drug Use and Breastfeeding. Pediatric Clinics of North America, 60, 275-294. https://doi.org/10.1016/j.pcl.2012.10.009

[48] Schanler, R.J., O’Connor, K.G. and Lawrence, R.A. (1999) Pediatricians' Practices and Attitudes Regarding Breastfeeding Promotion. Pediatrics, 103, E35. https://doi.org/10.1542/peds.103.3.e35

[49] Freed, G.L., Clark, S.J., Sorenson, J., Lohr, J.A., Cefalo, R. and Curtis, P. (1995) National Assessment of Physicians' Breast-Feeding Knowledge, Attitudes, Training, and Experience. JAMA, 273, 472-476. https://doi.org/10.1001/jama.1995.03520300046035

[50] Pound, C.M., Williams, K., Grenon, R., Aglipay, M. and Plint, A.C. (2014) Breastfeeding Knowledge, Confidence, Beliefs, and Attitudes of Canadian Physicians. Journal of Human Lactation, 30, 298-309. https://doi.org/10.1177/0890334414535507

[51] Freed, G.L., Clark, S.J., Lohr, J.A. and Sorenson, J.R. (1995) Pediatrician Involvement in Breast-Feeding Promotion: A National Study of Residents and Practitioners. Pediatrics, 96, 490-494. 